Supporting Information

\title{
High-performance water-borne polyurethane coating based on a blocked isocyanate with cellulose nanocrystals (CNC) as the polyol
}

Reaz A. Chowdhurya, Caitlyn M. Clarkson, Shikha Shrestha ${ }^{a}$, Sami M. El Awad Azrakª, Miran Mavlan $^{\mathrm{b}}$, Jeffrey P. Youngblood ${ }^{\mathrm{a}}{ }^{*}$

Authors addresses:

a. School of Materials Engineering, Purdue University, West Lafayette, IN 47907, United States of America

b. Department of Chemistry, Purdue University, West Lafayette, IN 47907, United States of America

*Corresponding authors

Email: jpyoungb@purdue.edu, Phone: +1 765-496-2294, Fax: +1 765 494-1204 


\section{Details for Preparation}

To determine the ratio of components in the nanocomposite coatings, films with ratios of cellulose nanocrystals (CNCs) to polyisocyanate (PIC) from 1:1 to 5:1, incrementally, were prepared and cured at the maximum cure temperature $\left(150^{\circ} \mathrm{C}\right)$. After preparation, films were submerged in water and then removed. After submerging films in water, the coatings were visually inspected to determine if the coating was intact after submersion. For coatings of 4:1 $\mathrm{CNC}$ :PIC or less the coating remained intact. Of the ratios tested, 4:1 CNC:PIC was chosen because it had the highest $\mathrm{CNC}$ concentration and remained intact after submersion. The highest $\mathrm{CNC}$ concentration was decided on as hardness was interest in the present study.

\section{Differential Scanning Calorimetry (DSC)}

Differential Scanning Calorimetry (DSC) was used to justify the selection of cure temperatures for the CNC-polyurethane composite coatings. A solution of 4:1 CNC:PIC was heated at $10^{\circ} \mathrm{C} / \mathrm{min}$ from $-25^{\circ} \mathrm{C}$ to $200^{\circ} \mathrm{C}$ to determine where reactions begin. Since deblocking of the PIC and the reaction of CNC with PIC happen simultaneously, the endothermic and exothermic signals corresponding to these phenomena cannot be easily de-coupled by DSC. However, it can be observed that above $70^{\circ} \mathrm{C}$, the deblocking process is well underway and that by $150^{\circ} \mathrm{C}$ it is finished. For this study, temperatures within this range were selected at $80^{\circ} \mathrm{C}, 120^{\circ} \mathrm{C}$, and $150^{\circ} \mathrm{C}$ to represent different moments in the cure cycle of $\mathrm{CNC}$ polyurethane nanocomposite coatings and investigate the effect of using different cure temperatures on coating performance. 


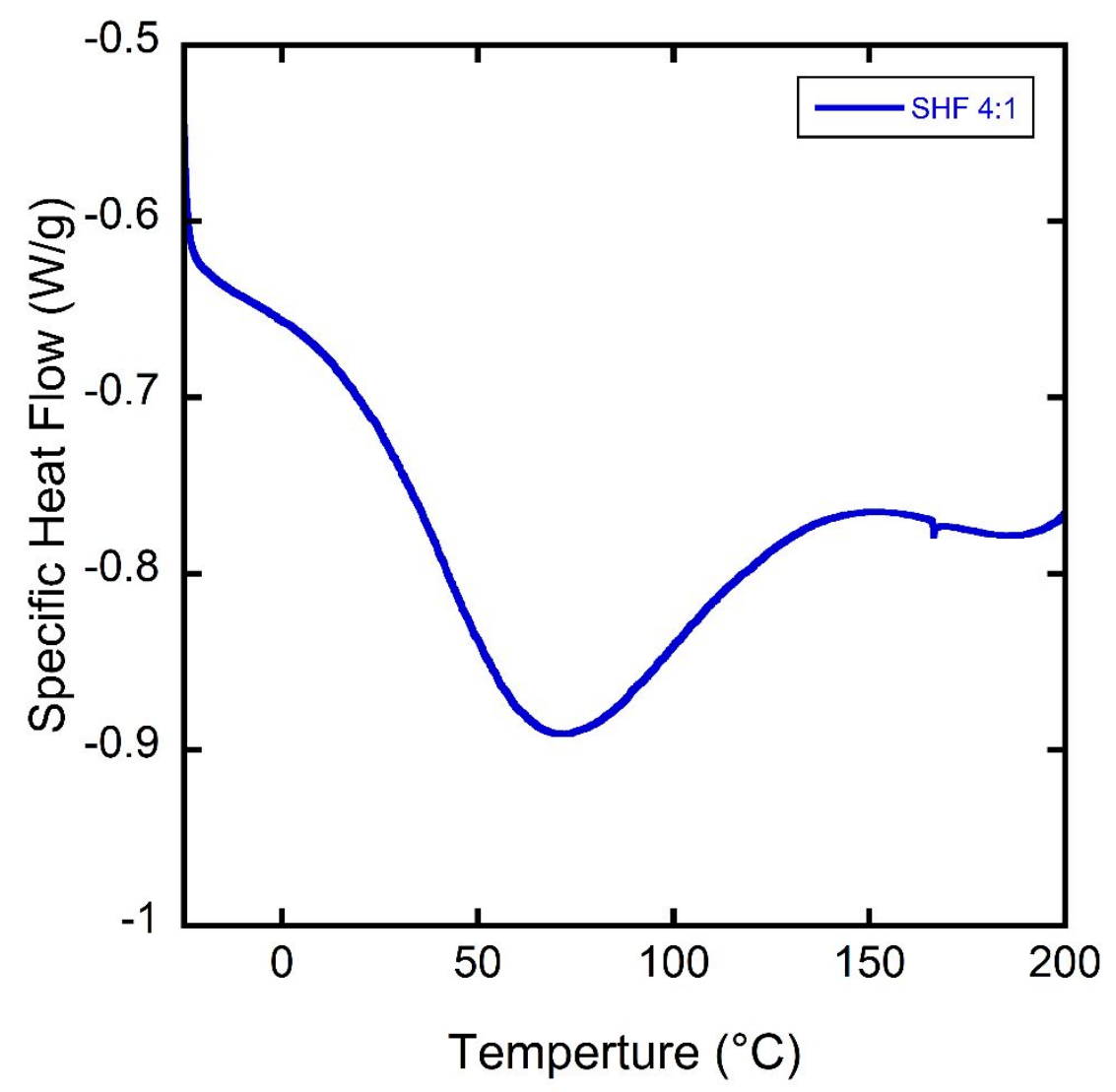

Figure S1. Differential scanning calorimetry (DSC) thermogram of CNC:PIC solution heated at $10^{\circ} \mathrm{C} / \mathrm{min}$ to observe thermal response.
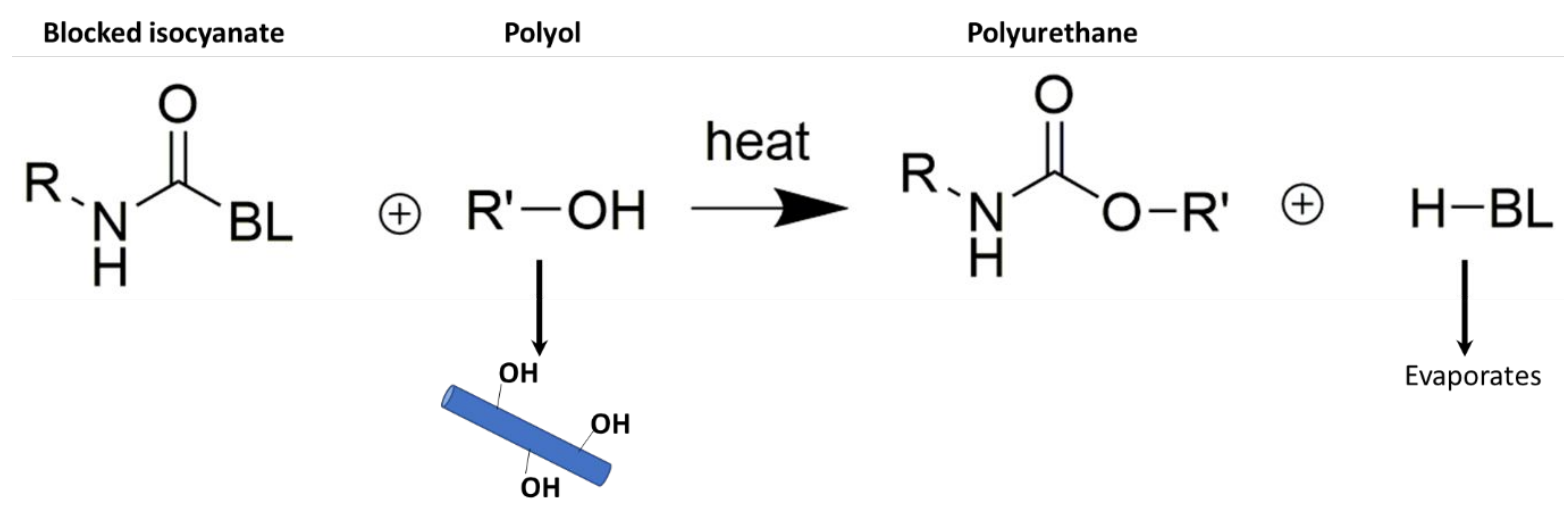

$\mathrm{CNC}$ with available surface $\mathrm{OH}$

Figure S2. Generic reaction of a blocked isocyanate with a polyol to form polyurethane. CNCs were used as the polyol as they have available $\mathrm{OH}$ to participate in the reaction. 
Table S1. Shore hardness values for various coating materials.

\begin{tabular}{|l|l|l|}
\hline Sample & Shore Hardness & Reference \\
\hline $\begin{array}{l}\text { Polycarbonate- } \\
\text { Urethane }\end{array}$ & $40 \mathrm{~A}$ & 1 \\
\hline PTMG-Urethane & $15 \mathrm{~A}$ & 1 \\
\hline PVC & $58 \mathrm{D}$ & 2 \\
\hline $\begin{array}{l}\text { Urethane } \\
\text { Acrylates }\end{array}$ & $25 \mathrm{D}$ & 3 \\
\hline $\begin{array}{l}\text { CNC } \\
\text { nanocomposite }\end{array}$ & $81 \mathrm{D}$ & This work \\
\hline
\end{tabular}
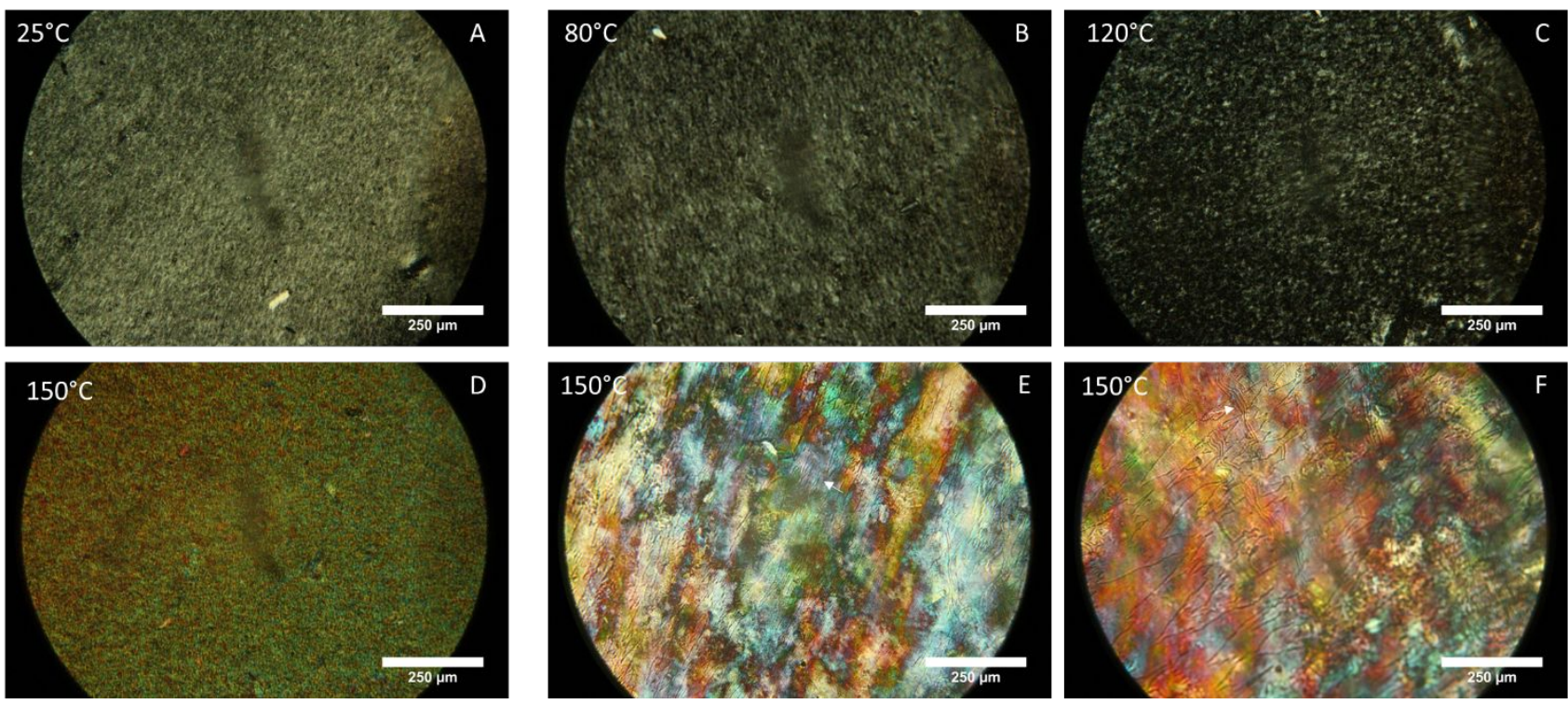

Figure S3. Polarized optical microscopy images of polyurethane/CNC composite coatings. Fast dried coatings cured at various temperatures A) $\left.25^{\circ} \mathrm{C} \mathrm{B}\right) 80^{\circ} \mathrm{C} \mathrm{C}$ ) $120^{\circ} \mathrm{C}$ and D) $150^{\circ} \mathrm{C}$ and very slow dried at $150^{\circ} \mathrm{C}$, shown here in two locations on the films E) Point 1 and F) Point 2 . Arrows show banded structures from drying process, potentially gradients in the sample as water evaporated. 


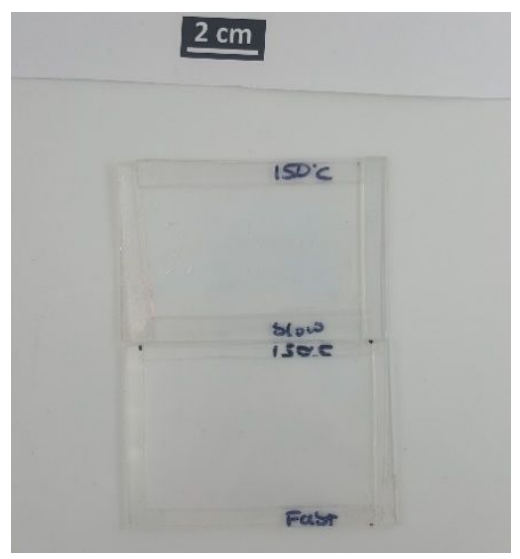

a

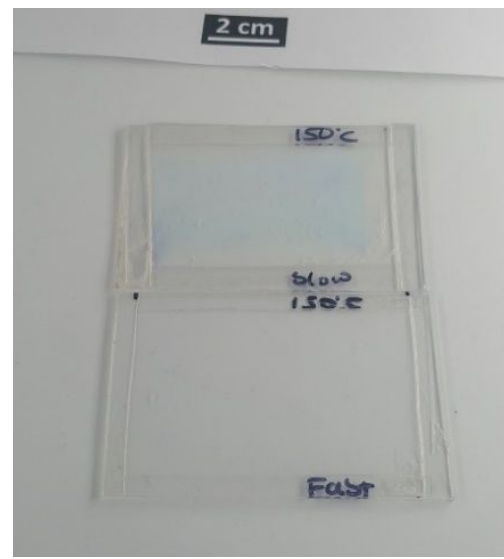

b

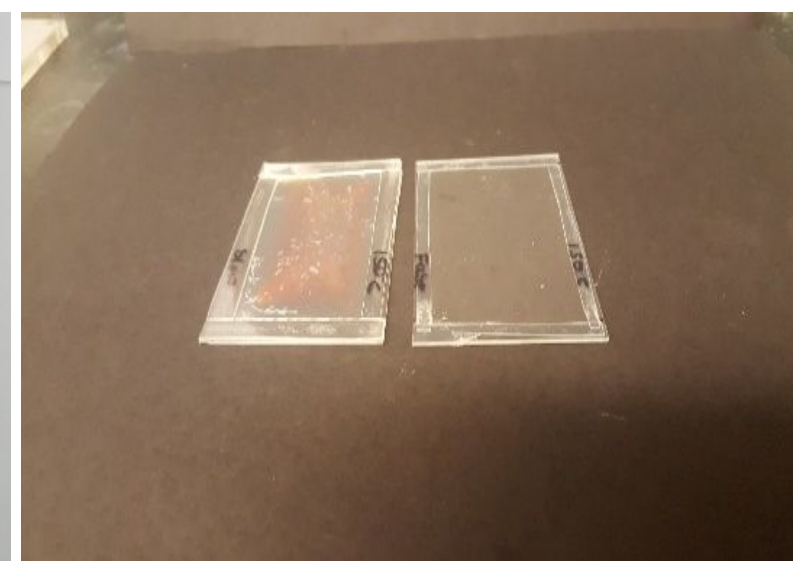

C

C

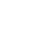

Figure S4. Samples with slow evaporation show angle-dependent iridescent property due to chiral nematic configuration. The slowly evaporated sample shows blue to redshift due to progression of tilt angle from low to high angle. Here, a) face on view (no color), b) low angle view (blue color), and c) high angle view (red color).

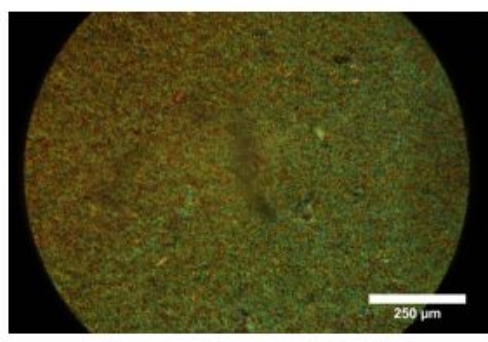

(a)

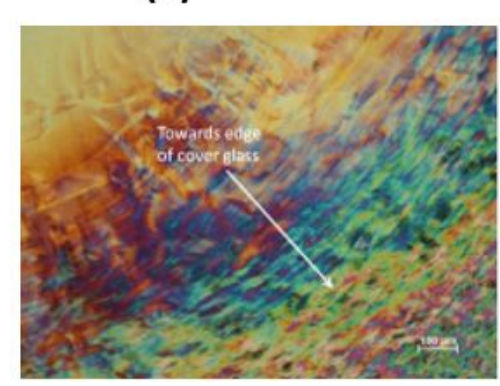

(C)

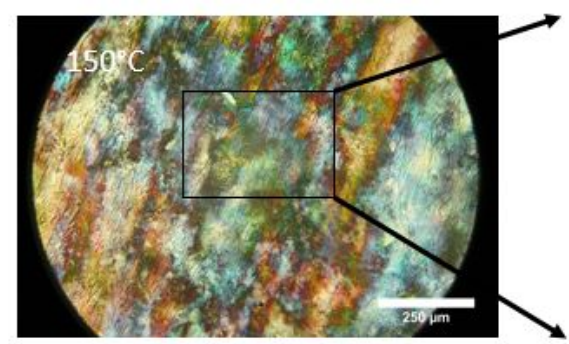

(b)

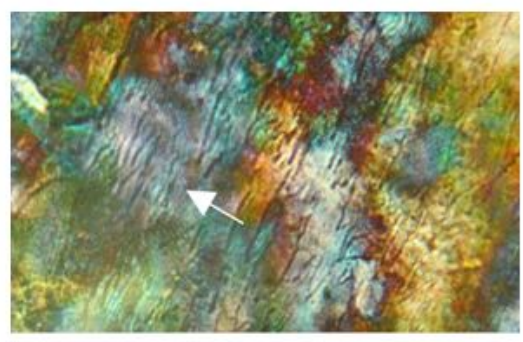

(b) 
Reference:

1. https://coatings.specialchem.com/centers/polycarbonate-diols-for-durable-pucenter/extreme-durability\#6

2. Yang, Y.; Huang, J.; Zhang, R.; Zhu, J. Designing Bio-Based Plasticizers: Effect of Alkyl Chain Length on Plasticization Properties of Isosorbide Diesters in PVC Blends. Mater. Des. 2017, 126, 29-36.

3. Wei, D.; Liao, B.; Yong, Q.; Li, T.; Wang, H.; Huang, J.; Pang, H. Castor Oil Based Hyperbranched Urethane Acrylates and Their Performance as UV-Curable Coatings. J. Macromol. Sci. Part A Pure Appl. Chem. 2018, 55 (5), 422-432.

4. Gray, D. G.; Mu, X. Chiral Nematic Structure of Cellulose Nanocrystal Suspensions and Films; Polarized Light and Atomic Force Microscopy. Materials (Basel). 2015, 8 (11), 7873-7888. 